\title{
Study and Physicochemical Characterization of the Diesel Particles Inducing Bronchopulmonary Obstructions and Inflammation
}

\author{
M. Bouzid $\dagger *$, A. Djadi** and B. Bezzazi* \\ *Research Unit: Materials, Processes and Environment, University M'Hamed Bougara, Boumerdes, Algeria \\ **Research Unit in Analysis and Technological Development in Environment, Center of Research in Physicochemical \\ Analyzes, Bousmail, Algeria \\ $†$ Corresponding author: M. Bouzid; technosante1@ hotmail.fr
}

Nat. Env. \& Poll. Tech. Website: www.neptjournal.com

Received: $17-10-2019$

Revised: $30-10-2019$

Accepted: 16-01-2020

Key Words:

Diesel soot particles

Pulmonary obstruction

Micro-Visiography

\section{ABSTRACT}

Micro-Visiography reveals that diesel soot particles are soluble in the physiological pulmonary liquid. It also shows that these substances stick to bronchial capillary walls. Electronic microscopy reveals structures of non-homogeneous morphology with spherical, fibrous and platelet-like structures. Analysis of the surfaces of the aggregates by Energy-dispersive X-ray microanalysis (EDX) shows the composition of chemical charges. Besides, X-ray diffraction and thermogravimetric study show the existence of two phases: organic and crystalline, with a rubber elastomer aspect. Infrared and UVVisible spectroscopic analysis confirmed the existence of reactive chemical groups.

\section{INTRODUCTION}

Air pollution poses intriguing questions ( $\mathrm{Li}$ et al. 2016, Xu-Qin et al. 2016, Fanny et al. 2012, Zorana et al. 2011, Devries et al. 2016). Recently, important studies of the invitro behaviour of diesel particles in physiological fluids of the lungs have been reported. The visual graphic scan of a laboratory rabbits' lungs, exposed to small doses of diesel exhaust fumes, revealed an inflammation aspect induced by the presence of DEPs (Bouzid et al. 2017). The authors measured the electric charge of the particles and showed a close relationship with a new form of obstruction in the bronchial tree "suction cup effect". These mechanisms rise from electrostatic interactions with bronchi and bronchiole walls in the lung (Bouzid et al. 2017). Renewed interest in the inflammation aspect of the respiratory tract caused by the presence of DEPs has been described in the literature (Boland et al. 2001, Habert \& Garnier 2015). These results are in perfect agreement with epidemiological studies. The incidence of allergic diseases is also associated with the presence of DEPs. Short-term exposure is sufficient to increase cardiorespiratory morbidity whereas chronic exposure may cause asthma, obstructive chronic bronchopneumopathy, lung cancer, and cancer of the bladder (Brewer et al. 2016, Hart et al. 2006, Traboulsi et al. 2017). The toxicity of diesel particles is linked to their capacity to cause oxidizing stress at the cellular level (Borgie et al. 2015, Aloui et al. 2016). The metabolism of HAP by $\mathrm{P} 450$ cytochrome, epoxide hydrolase and dihydrodiol dehydrogenase (DHDH) produces DNA adducts which can lead to the development of various types of cancer (Aloui et al. 2016). Since 2012, exhaust fumes have been classified by the WHO as carcinogens (WHO 2013). To understand the mechanism of action of DEPs, the physico-chemistry element is essential. Stanmore et al. (2001) published a micrograph of diesel soot in which we can clearly distinguish the fractal form agglomerations. On the other hand, Yapp et al. (2013) presented a model of the formation of soot during combustion. Nanometric clusters were investigated by Transmission Electron Microscopy (TEM) (Fig. 1). This proposal is supported by theoretical studies. The soot particles are rich in carbon, NOx, anhydrous sulphurous $\mathrm{SO}_{2}$ and its derivatives, polycyclic aromatic hydrocarbons, oxygenated organic compounds (phenols, alcohols, aldehydes ketones). These products agglomerate around mineral carbon crystallites (Richter \& Howar 2000).

The available literature is oriented towards modelling the partial behaviour in the lungs (de Vasconcelos et al. 2011), the formation of soot, analysis of reaction mechanisms, the chemical composition of the particle and its physicochemical properties (Abul \& Shahidul 2013, Akridis \& Rigopoulos 2016).

The objective of this work is a physicochemical analysis of diesel particles involved in broncho obstruction and 

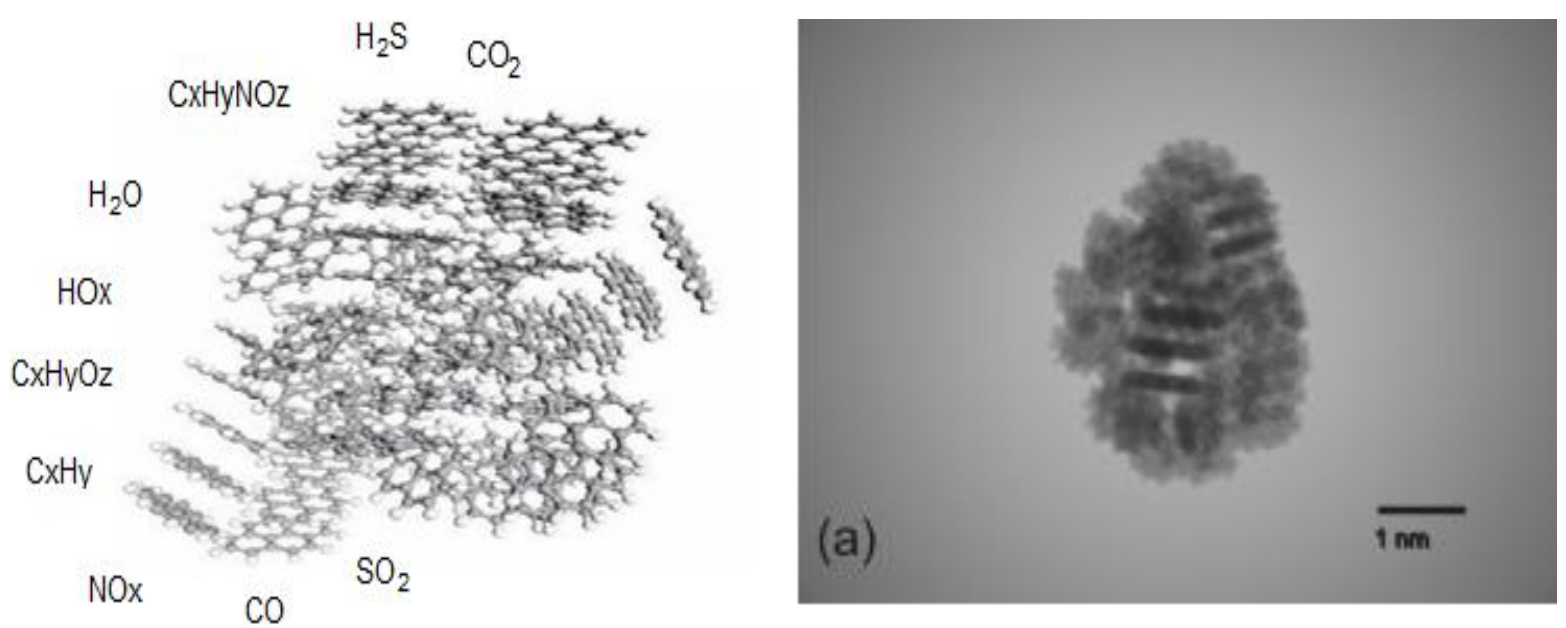

Fig. 1: Image of an aggregate of a diesel particle and model of HAP molecules involved in the formation of soot.

inflammation of laboratory rabbit lungs. This contribution identifies the solubility of the diesel particles in physiological pulmonary solutions by visiography. Microscopic and physicochemical studies can explain this behaviour.

\section{MATERIALS AND METHODS}

Diesel particles and pulmonary surfactant came from "Health Technology Algeria", Ministry of Health.

\section{Observation by Scanning Electron Microscope (SEM)}

Several high-resolution pictures were taken of each sample in several zones and at different magnifications (400-20000 times). Selected parameters were pressure: 60 Pascal; beam of primary electrons: 5 and $10 \mathrm{Kv}$; electronic vessel (spot): between 3 and 3.5: secondary electron detector: (LFD); working distance: 7.9-9.9 mm; 400-200000 mm.

\section{Analysis by Energy Dispersive X-ray Microanalysis (EDX)}

Collection of spectra and elementary identification were performed by "global" mode which allowed for the identification of all the investigated elements.

The results of the microanalysis illustrate the presence of all the components sought for in form of spectrum provided with a summary table giving the mass and atomic percentages of each element.

PANalytical diffractometer: XPERT-PRO, copper anticathode ceramic radiation emitting tube, $X$-ray generator; power: $40 \mathrm{~mA}, 45 \mathrm{Kv}$. Software used for data acquisition: Data Collector from PANalytical; Data processing software: High Score Plus from PANalytical; Wavelength $\mathrm{CuK} \alpha$ $[\AA]$ : 1.5418; Starting angle [ $\left.{ }^{\circ} 2 \mathrm{Th}\right]:$ 2.0000; Final angle
[ $\left.{ }^{\circ} 2 \mathrm{Th}\right]: 70.0000 ;$ Step size [ $\left.{ }^{\circ} 2 \mathrm{Th}.\right]:$ $0.0170 ;$ Step time [S]: 91.7599 .

\section{Analysis by Infra-red Absorption Spectroscopy}

The infra-red absorption spectrophotometry was carried out on pastilles made up of $1 \mathrm{mg}$ of product dispersed in $300 \mathrm{mg}$ of $\mathrm{KBr}$ using a Nicolet 5700 series equipment.

\section{Analysis by Ultra Violet-Visible Absorption Spectroscopy}

UV-Visible analysis was carried out using a standard spectrophotometer Lambda EZ210. Scanning varied between 190 and $1100 \mathrm{Nm}$ of infinitely diluted solutions enables the determination of the absorption band of the products.

\section{Thermogravimetric Analysis}

To study the thermal properties, samples of approximately $2 \mathrm{mg}$ were measured using a Seiko SC 5200 thermoanalyser (model $220 \mathrm{TG} / \mathrm{DTA}$ ) at heating and flow rates of $10-50^{\circ} \mathrm{C} /$ $\mathrm{min}$ and $100 \mathrm{~mL} / \mathrm{min}$ respectively.

\section{RESULTS AND DISCUSSION}

The behaviour of DEPs in physiological solution clearly shows the dissolution of the organic matter in form of a violet fog around the particles which dissipate (Fig. 2). Laser diffraction granulometry of the DEP powder reveals on average a specific surface of $1.85 \mathrm{~m}^{2} / \mathrm{g}$ and a diameter of $10 \mu \mathrm{m}$ (Devries et al. 2016, Bouzid et al. 2017).

SEM micrographs of the diesel soot particles sample at 50 $\mu \mathrm{m}$, considered as carbon gas (DEP), obtained by thermolysis are shown in Figs. 3 and 4. The morphology of the DEP deposit surface is non-homogeneous. We can observe spherical 

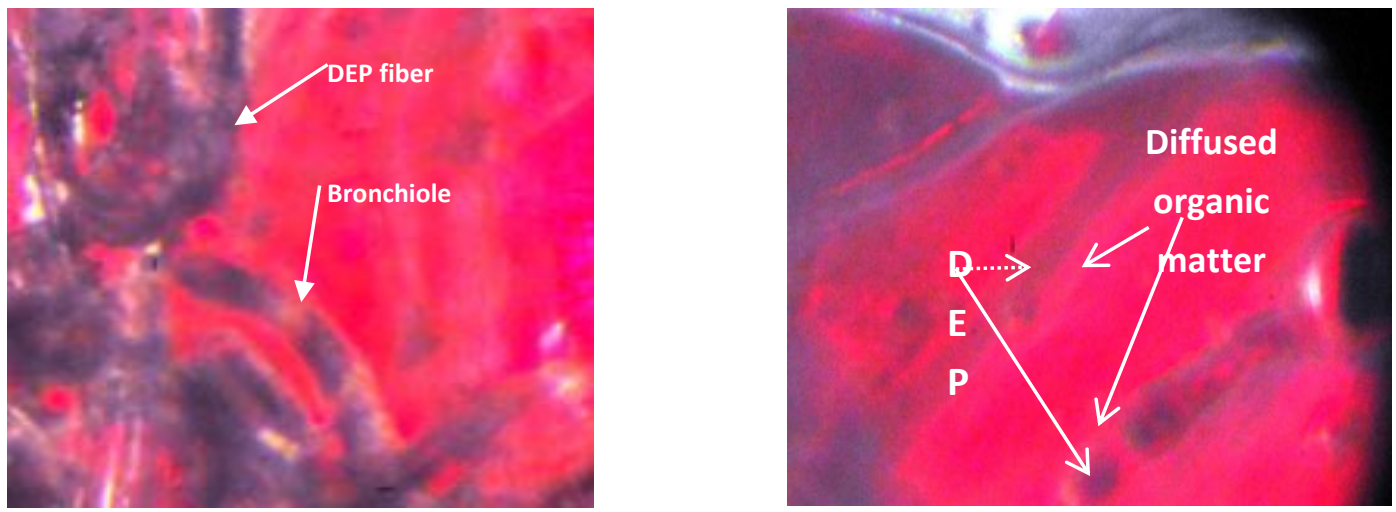

Fig. 2: Visio-scanography of DEP in physiological solution (optical filter $700 \mathrm{Nm}$ ).

carbon nanograins of variable diameters. The spheres meet to form randomly distributed wavelets. Furthermore, we can also see fibrous shapes of exhaust fumes in Fig. 4. Platelets forms appear on the two negatives.

The EDX spectrum (Fig. 5) of the surface of the diesel particle samples proves the presence of atomic elements on their surface. Table 1 summarizes the mass and atomic percentages in each case.

As can be seen from Table 1, carbon and oxygen represent high percentages. The quantity of chloride and sodium is relatively important and is induced by marine footprint. In gasoline, sulphur is usually found in small quantities.

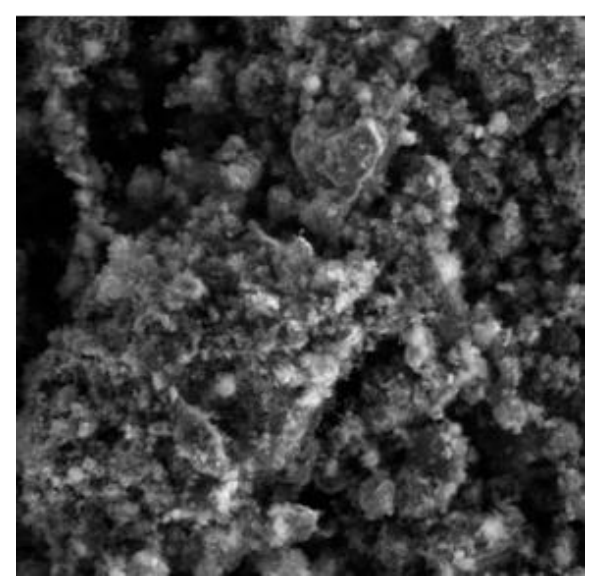

Fig. 3: SEM Spherical and platelet forms of DEP $(30 \mu \mathrm{m})$.

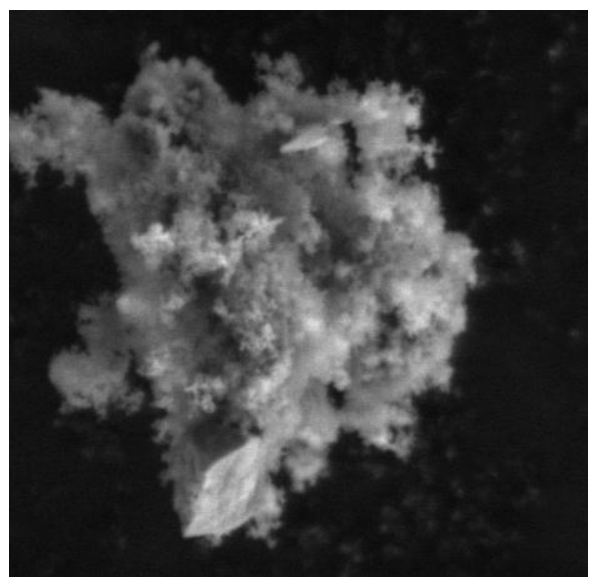

Fig. 4: SEM Fibrous Form of DEP $(4 \mu \mathrm{m})$.

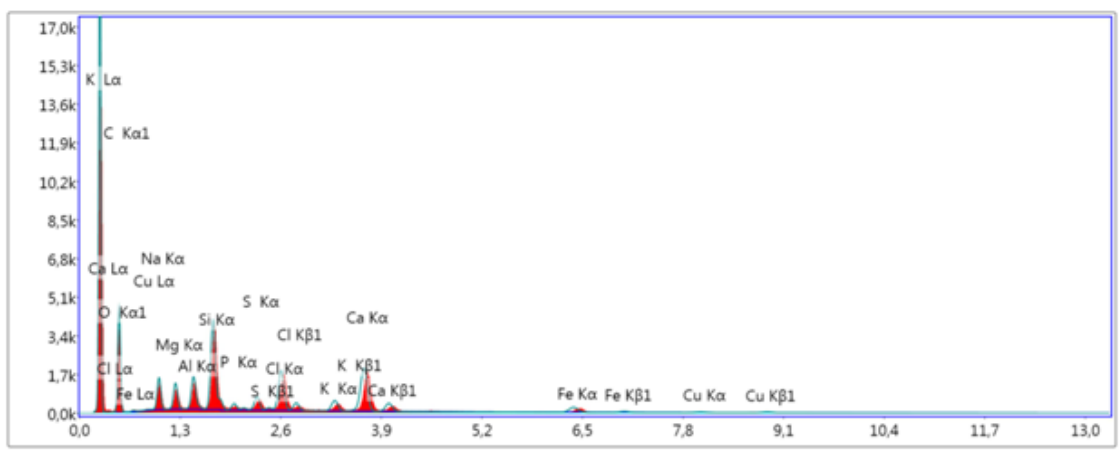

Fig. 5: Energy dispersive X-ray microanalysis of DEP. 
Metals result from wear of machine parts. The remainder of the atoms probably accentuates air contamination.

The X-rays diffraction spectrum (Fig. 6) reflects the two phases which constitute the diesel particles, the amorphous phase made up of an organic part and a crystalline phase primarily made up of mineral and carbon crystallite (Akridis \& Rigopoulos 2016).

Thermogravimetry confirms the XRD results. It quantifies the phases: organic matter $26.5 \%$ (evaporable matter) and crystalline inorganic matter $70 \%$ (Violi \& Sarofim 2001). The organic substance (unburnt residues, HAP) makes up the mineral phases. This constitution explains the elastomer aspect which is expressed in the range $\left(25-250^{\circ} \mathrm{C}\right)$ (Fig. 7$)$.

\section{Analysis by Infrared Spectroscopy}

The Infrared spectrum (Fig. 8), shows signals on the 4000$1500 \mathrm{~cm}^{-1}$ region which contains longitudinal vibration bands of the main $\mathrm{CH}$ groups, O-H, C=O, N-H, .. Peak $3445 \mathrm{~cm}^{-1}$ corresponds to the '-OH' group whereas the peak $2922 \mathrm{~cm}^{-1}$ corresponds to the ' $\mathrm{CH}$ ' group. We observed bands that are more or less broad because of the existence of a hydrogen bond. In the vicinity of $1550 \mathrm{~cm}^{-1}$, it is probably the $\mathrm{C}=\mathrm{C}$ that is expressed. Despite the complex structure of the soot particle, the infra-red remains readable and constitutes a reliable footprint.

\section{Study by UV-Visible Spectroscopy}

In solution, infinitely diluted in spectroscopic pentane, diesel

Table 1: Summary of mass and atomic percentages of each element.

\begin{tabular}{|lllll|}
\hline Elements & Mass $\%$ & Atomic $\%$ & Total Intensity & Error $\%$ \\
\hline $\mathrm{C}, \mathrm{K}$ & 63.29 & 74.54 & $4,572.00$ & 7.59 \\
$\mathrm{O}, \mathrm{K}$ & 20.78 & 18.37 & $1,230.28$ & 10.18 \\
$\mathrm{Na}, \mathrm{K}$ & 2.12 & 1.30 & 524.57 & 7.91 \\
$\mathrm{Mg}, \mathrm{K}$ & 1.05 & 0.61 & 459.78 & 6.78 \\
$\mathrm{Al}, \mathrm{K}$ & 1.17 & 0.61 & 617.34 & 5.02 \\
$\mathrm{Si}, \mathrm{K}$ & 3.06 & 1.54 & $1,851.57$ & 3.29 \\
$\mathrm{P}, \mathrm{K}$ & 0.21 & 0.10 & 110.63 & 8.97 \\
$\mathrm{~S}, \mathrm{~K}$ & 0.54 & 0.24 & 299.07 & 4.68 \\
$\mathrm{Cl}, \mathrm{K}$ & 2.00 & 0.80 & $1,008.77$ & 2.22 \\
$\mathrm{~K}, \mathrm{~K}$ & 0.66 & 284.23 & 4.74 \\
$\mathrm{Ca}, \mathrm{K}$ & 3.62 & 0.24 & $1,305.82$ & 2.03 \\
$\mathrm{Fe}, \mathrm{K}$ & 1.20 & 1.28 & 196.82 & 5.87 \\
$\mathrm{Cu}, \mathrm{K}$ & 0.31 & 0.30 & 30.34 & 17.48 \\
\hline
\end{tabular}

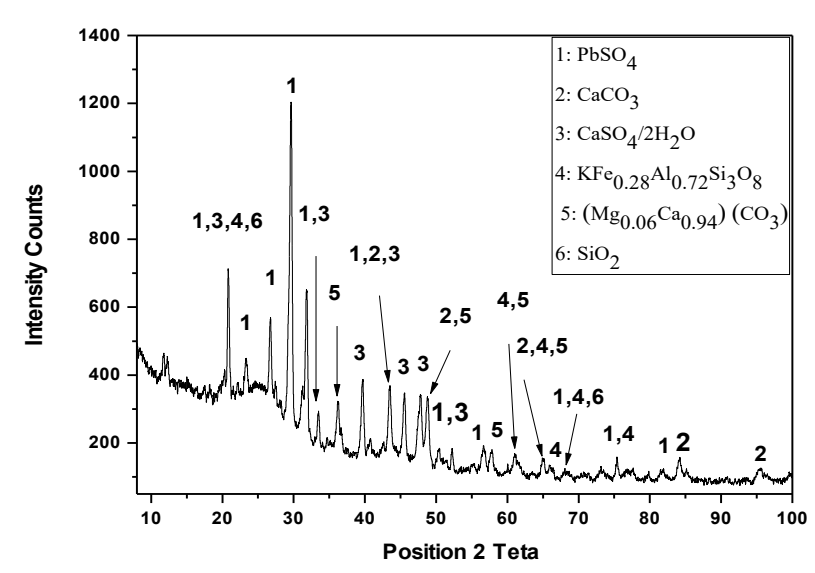

Fig. 6: X-ray diffraction spectrum of DEP.

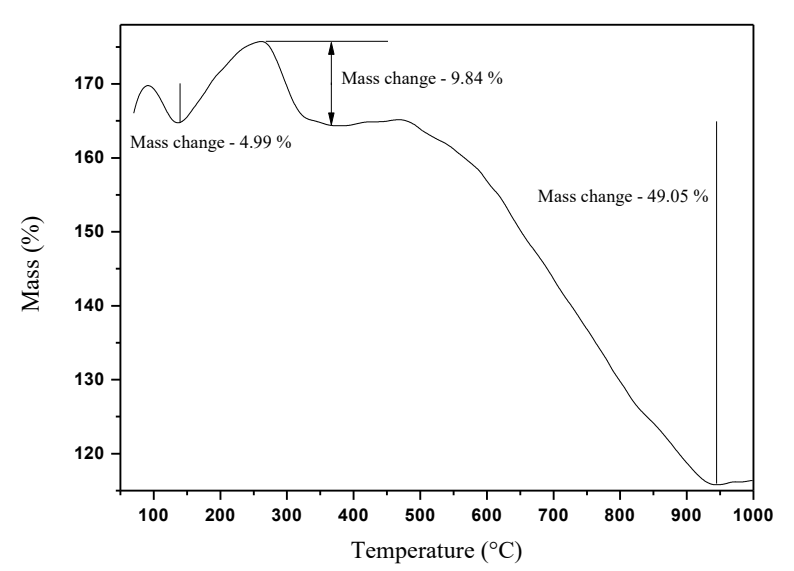

Fig. 7: Thermogravimetry of DEP. 


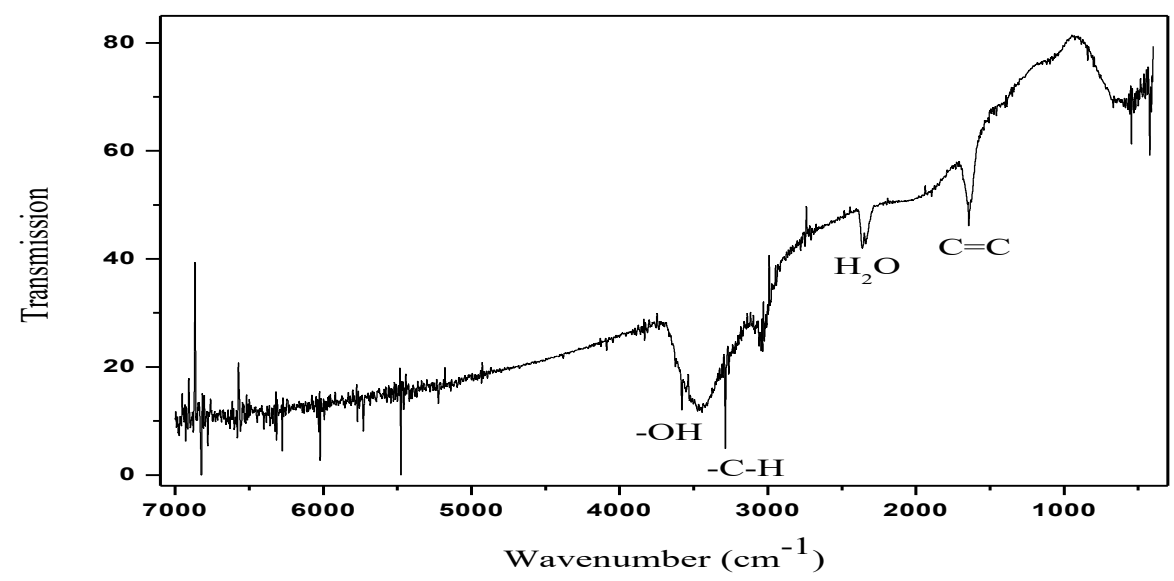

Fig. 8: Infra-red spectrum of DEP.

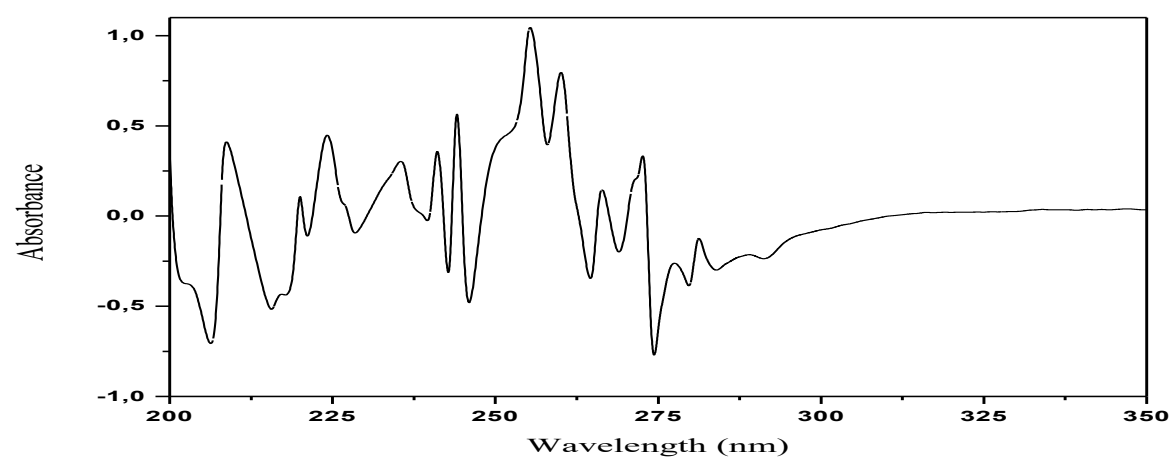

Fig. 9: UV-Visible spectrum of DEP in cyclohexane solution.

particles are partly dissolved. This type of solubility of many organic molecules gives a saw-teeth spectrum (Fig. 9).

\section{CONCLUSION}

The study by electronic microscopy highlights the aspects of exhaust diesel fumes. The gases consist of aggregates of spherical, platelet and fibrous forms. Associated EDX analysis, shows the presence of chemical elements in the fabric of soot. Micro-visiography of diesel soot in physiological solution reveals an instantaneous dissipation of organic substances in the physiological liquid. XRD indicates the presence of two phases: Amorphous, and crystalline in the same particle. Thermogravimetry highlights the elastomer aspect of the DEP particle. It confirms the existence of two phases and also, primarily quantifies organic and inorganic matter. Infrared and UV-Visible spectroscopy determines the reactive chemical functions present. Diesel particles have a complex composition. They penetrate the lung and are physically highly reactive due to the crystallites (effects of shearing). Besides, they are chemically highly reactive due to the reactivity of chemical charges of HAP and their derivatives.

\section{REFERENCES}

Abul, H M. and Shahidul, I. 2013. Synthesis of carbon nanoparticles from kerosene and their characterization by SEM/EDX, XRD and FTIR. American Journal of Nanoscience and Nanotechnology, 1(2): 52-56.

Akridis, P. and Rigopoulos, S. 2016. Modelling of soot formation in laminar diffusion flames using a comprehensive CFD-PBE model with detailed gas-phase chemistry. Combustion Theory and Modelling, 21(1): 35-48.

Aloui, R., Magne, F., Devouassoux, G., Deverchere, J., Ritter, P., Bentaher, A. and Pacheco, Y. 2016. Effects of fine particulate matter from on bronchial epithelialcells. Revue Des Maladies Respiratoires, 33(9): 767-774.

Boland, S., Baeza, A. and Francelyne Marano, S. 2001. Toxicité respiratoire des particules Diesel : les mécanismes cellulaires et moléculaires. Médecine/Sciences, 17: 596-603.

Bouzid, M., Djadi, A., Guetaf, H. and Bezzazi, B. 2017. Air pollution from diesel particles and chronic obstructive pulmonary disease - CT scan study. European Scientific Journal, 13(6): 504-512.

Borgie, M., Ledoux, F., Verdin, A., Cazier, F., Greige, H., Shirali, P., Courcot, D. and Dagher, Z. 2015. Genotoxic and epigenotoxic effects of fine particulate matter from rural and urban sites in Lebanon on human bronchial epithelial cells. Environmental Research, 136: 352-362.

Brewer, K., Egyed, M., Huang, L., Ling, B., Matz, C. and Rouleau, M. 2016. Human Health Risk Assessment for Diesel Exhaust, ISBN: 978-0-66004556-6, Cat.: H129-60/2016F-PDF, Pub.: 150240.

DeVries, R., Kriebel, D. and Sama, S. 2016. Low level air pollution and exacerbation of existing COPD: A case crossover analysis. Environmental Health, 15(1): 1-11. 
Yapp, E.K. and Kraft, M., 2013. Modelling soot formation: Model of particle formation. In: Cleaner Combustion Springer, London, pp. 389-407.

Fanny, W.S., Ko. David and Hui, S.C. 2012. Air pollution and chronic obstructive pulmonary disease. Respirology, 17: 395-401.

Habert, C. and Garnier, R. 2015. Health effects of diesel exhaust: A state of the art. Revue des Maladies Respiratoires, 32: 138-154.

Hart, J.E., Laden, F., Schenker, M.B. and Garshick. E. 2006. Chronic obstructive pulmonary disease mortality in diesel-exposed railroad workers. Environmental Health Perspectives, 114(7): 1013-1017.

Li, J.H., Sun, S.Z., Tang, R., Qiu, H., Huang, Q.Y., Mason, T.G. and Tian, LW. 2016. Major air pollutants and risk of COPD exacerbations: a systematic review and meta-analysis. International Journal of Chronic Obstructive Pulmonary Disease, 11(1): 3079-3091.

Richter, H. and Howar, J.B. 2000. Formation of polycyclic aromatic hydrocarbons and their growth to soot - A review of chemical reaction pathways. Prog. Energy Combust. Sci., 26: 565-608.

Stanmore, B.R., Brilhac, J.F. and Gilot, P. 2001. The oxidation of sootexperiments, mechanisms and models. Carbone, 39: 2247-2268.

Traboulsi, H., Guerrina, N., Iu, M., Maysinger, D., Ariya, P. and Baglole, C.J. 2017. Inhaled pollutants: The molecular scene behind respiratory and systemic diseases associated with ultrafine particulate matter. Int. J. Mol. Sci., 18(243): 1-19.
Vasconcelos, T.F. DE., Sapoval, B., Andrade, J. S., James J.R., Grotberg, B., Yingying, H.U. and Filoche, M. 2011. Particle capture into the lung made simple. Journal of Applied Physiology, 111: 1664-1673.

Violi, A. and Sarofim, A.F. 2001. Quantium mechanical study of molecular weight growth process by combination of aromatic molecules. Combustion and Flame, 126: 1506-1515.

WHO 2013. Review of evidence on health aspects of air pollution REVIHAAP project. Technical report, World Health Organization.

Xu-Qin, J., Xiao-Dong, M. and Di, F. 2016. Air pollution and chronic airway diseases: What should people know and do? J. Thorac. Dis., 8(1): 31-40.

Zorana, J., Andersen, M., Hvidberg, S., Jensen, S., Ketzel, M., Loft, S., Sørensen, M., Tjønneland, A., Overvad, K. and Raaschou-Nielsen, O 2011. Chronic obstructive pulmonary disease and long-term exposure to traffic-related air pollution: A cohort study. American Journal of Respiratory and Critical Care Medicine, 183(4): 455-461. 